\title{
Design of Z-Shape Compact Antenna for Next Generation Wireless Network
}

\author{
Swarnaprava Sahoo \\ Department of Electronics and \\ Communication Engineering \\ ITER, Siksha 'O' Anusandhan \\ University, Bhubaneswar, Odisha \\ Email:swarna.sahoo@gmail.com
}

\author{
Mihir Narayan Mohanty \\ Department of Electronics and \\ Communication Engineering \\ ITER, Siksha 'O' Anusandhan \\ University, Bhubaneswar, Odisha \\ Email: \\ mihirmohanty@soauniversity.ac.in
}

\author{
Rabindra Kumar Mishra \\ Department of Electronics Science \\ Berhampur University, \\ Berhampur, Odisha \\ Email: rkmishra.ieee@gmail.com
}

\begin{abstract}
The wireless communication technology is developing day by day so that various generations are taken birth. The fifth generation is considered as the next generation network and awaiting for implementation. Considering this scenario, compact antenna plays a vital role to make this dream to be realized. In this research work authors have taken a strive to design such required antenna where the bandwidth has been enhanced. The two different frequencies range covers up to fourth generation networks and beyond. Similarly, the bandwidth has been enhanced up to $75 \mathrm{MHz}$ and $112.5 \mathrm{MHz}$ which is approximately doubles the value of the current bandwidth. The antenna has to be pasted in the mobile circuit to maintain the data transfer in seamless mode. For suitability of the space $Z$-shape micro strip antenna has been developed. The result shows the achievement in terms of bandwidth, return loss, VSWR, directivity and gain. It is of $\mathrm{C}$ - band/ S-band satellite communication for application in wireless communication.
\end{abstract}

Keywords-Next generation Network, Micro strip antenna, dual band antenna, broadband antenna, wireless communication

\section{INTRODUCTION}

THE patch radiators are in demand for their enchanting properties such as small profile, easy fabrication, low weight and compatibility with Monolithic Microwave Integrated Circuits (MMICS). Due to compact and planar structures [1$3]$, the microstrip patch radiators are used in mobile and satellite communication, wireless and in wide range of microwave equipments. The disadvantage of it is narrow band width due to resonant creation of the radiating element shape. The rigorous experimentation has been developed for bandwidth enhancement of patch antenna [4-6]. The common techniques for bandwidth enhancement are heightening substrate thickness, addition of parasitic elements to radiating element, lower dielectric substrate, use of different impedance matching and feeding methods, by several resonators and slot radiator geometry are innumerable and familiar techniques [7-10]. The work has been performed by Ansoft High Frequency System Simulator (HFSS).

In this work the two wide rectangular slits are inserted at the opposite faces of the non radiating edges of patch which is approximately equal to the length of patch. The two slits of separation are placed symmetrically w. $r . t$ the patch center line (axis of $\mathrm{x}$ and $\mathrm{y}$ ). So, for the wide slits there are three parameters $\left(\mathrm{L}_{7}=\mathrm{L}_{1}, \mathrm{~L}_{6}=\mathrm{L}_{2}\right.$ and separation) used here to mainly perturb the excited patch surface current path. When slot is inserted at centre of the patch the flow of current density will go by diverting the direction, in which bandwidth will be more compared to conventional patch.

The rest of the work is arranged as follows: section II dispenses design procedure for Z- shape patch antenna, details of simulation results are stated in section III and at last section IV concludes the work.

\section{ANTENNA Design}

\section{A. Method of Design}

Microstrip patch antenna consists of a very thin of $t<<\lambda_{0}$ metallic strip called radiating element placed on a dielectric substrate of height restricted by the height $0.0003 \lambda_{0} \leq \mathrm{h} \leq \lambda_{0}$ where $\lambda_{0}$ is the free space wavelength. The microstrip radiator is devised so that its maximal radiation pattern is normal to the patch. For a rectangular microstrip radiator length (L) of the radiating element is generally $\frac{\lambda_{0}}{3}<L<\frac{\lambda_{0}}{2}$ .The dimension has major impact on operating frequency [11-14].

\section{B. Design Procedure}

Using proper choice of thickness, properties of dielectric substrate and antenna shape, the radiator bandwidth is mainly deliberated. To reveal the band width in plain planar structures and to give standard basis in terms of space and bandwidth, rectangular microstrip patch radiator has been first developed. The dimensions of the radiator can be derived from empirical formulas [1], [4].

(a) Width of Patch: $\mathrm{W}=\frac{c}{2 f_{0}} \sqrt{\frac{2}{\epsilon_{\gamma}+1}}$

(b) Effective Dielectric Constant: 
$\epsilon_{r e f f}=\frac{\epsilon_{r}+1}{2}+\frac{\epsilon_{r}-1}{2}\left[1+12 \frac{h}{W}\right]^{\frac{-1}{2}}$

(c) Due to fringing effects the change in dimension of length:

$\Delta L=0.412 h \frac{\left(\epsilon_{\text {reff }}+0.3\right)\left(\frac{W}{h}+0.264\right)}{\left(\epsilon_{\text {reff }}-0.258\right)\left(\frac{W}{h}+0.8\right)}$

(d) Length of Patch: $\mathrm{L}=\frac{c}{2 f_{0} \sqrt{\epsilon_{\mathrm{raff} f}}}-2 \Delta L$

Where $\epsilon_{\Upsilon}=$ Dielectric constant

$\mathrm{h}=$ Substrate thickness, $f_{0}=$ Resonant frequency

One of factors for bandwidth controlling is increasing antenna width. Nevertheless, to get acceptable result with simple rectangular microstrip patch antenna is very difficult So, Z-shape geometry is proposed to widen the antenna impedance bandwidth while keeping reasonable dimensions. Multiple resonances are generated due to change in distribution of surface current density.

The aim of antenna design at 3.3 and $4.2 \mathrm{GHz}$ was to get better performance for next generation wireless network application. The width of the radiating element is usually chosen to be larger than length of the patch to get higher bandwidth. To design patch antenna lower dielectric constant is used because in case of lower dielectric constant of the substrate, surface wave losses are more severe and dielectric and conductor losses are less severe. Table 1 shows the specifications for the proposed microstrip patch antenna.

\section{Design of Z-shape micro strip patch antenna}

The width (W), length (L) of radiating element, transmission line width and length are most important features for the designing of antenna. The patch is fed by a $50 \Omega$ inset feed. The two wide rectangular slits are of lengths $\mathrm{L}_{1}$ and $\mathrm{L}_{7}$ and of width $\mathrm{L}_{2}$ and $\mathrm{L}_{6}$ are inserted at the opposite faces of the non radiating edges of patch which is approximately equal to the length of patch. The two slits of separation are placed symmetrically w. $r$. $t$ to the patch center line (axis of $\mathrm{x}$ and $\mathrm{y}$ ). So, for the wide slits there are three parameters $\left(\mathrm{L}_{7}=\mathrm{L}_{1}, \mathrm{~L}_{6}=\mathrm{L}_{2}\right.$ and separation) used here to mainly perturb the excited patch surface current path.
TABLE 1. DIMENSIONS OF PROPOSED ANTENNA

\begin{tabular}{|c|c|}
\hline Parameter & Value \\
\hline Substrate & FR4- ероху \\
\hline Center frequency $\left(f_{r}\right)$ & $2.32 \mathrm{GHz}, 3.62 \mathrm{GHz}$ \\
\hline Substrate height (h) & $1.6 \mathrm{~mm}$ \\
\hline Loss tangent & 0.02 \\
\hline Dielectric constant $\left({ }^{\varepsilon_{r}}\right)$ & 4.4 \\
\hline $\begin{array}{l}\text { Width of radiating element } \\
\text { (W) }\end{array}$ & $38.04 \mathrm{~mm}$ \\
\hline $\begin{array}{l}\text { Length of radiating } \\
\text { element }(\mathrm{L})\end{array}$ & $29.44 \mathrm{~mm}$ \\
\hline Feed width $\left(\mathrm{w}_{0}\right)$ & $1.8 \mathrm{~mm}$ \\
\hline $\mathrm{y}_{0}$ & $5 \mathrm{~mm}$ \\
\hline $\mathrm{x}_{0}$ & $0.6 \mathrm{~mm}$ \\
\hline \multicolumn{2}{|c|}{ Dimensions of $Z$-shape patch antenna } \\
\hline Parameter & Value \\
\hline $\mathrm{L}_{1}$ & $30 \mathrm{~mm}$ \\
\hline $\mathrm{L}_{2}$ & $5 \mathrm{~mm}$ \\
\hline $\mathrm{L}_{6}$ & $6 \mathrm{~mm}$ \\
\hline $\mathrm{L}_{7}$ & $32 \mathrm{~mm}$ \\
\hline
\end{tabular}


When slot is inserted at centre of the patch the flow of current density will go by diverting the direction, in which bandwidth will be more compared to conventional patch. The geometry and configuration of Z-shape microstrip patch radiator is presented in Fig. 1 and Fig. 2. The length of the Ishaped slot is $30 \mathrm{~mm}$ which is symmetrical to $\mathrm{x}$ - axis and width of patch is approximately equal to the length of $\mathrm{L}_{1}$ and $\mathrm{L}_{7}$ which is calculated from the relation

$$
\mathrm{L}<\frac{\lambda_{0}}{2}
$$

Because the slot length depends on the centre frequency, substrate dielectric constant.

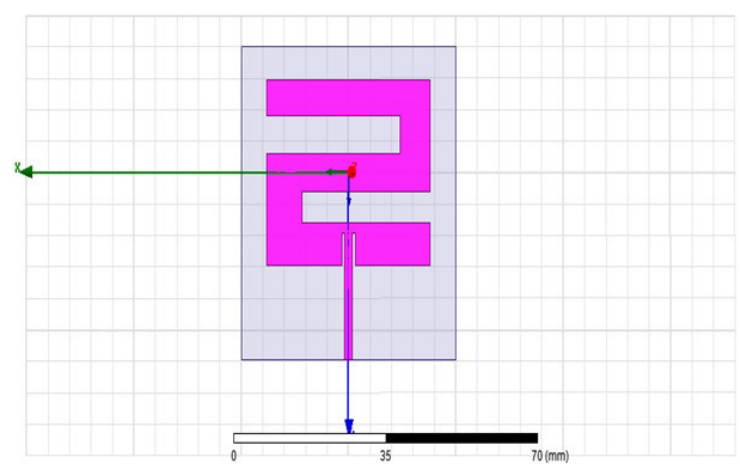

Fig 1. Z- Shape microstrip patch antenna

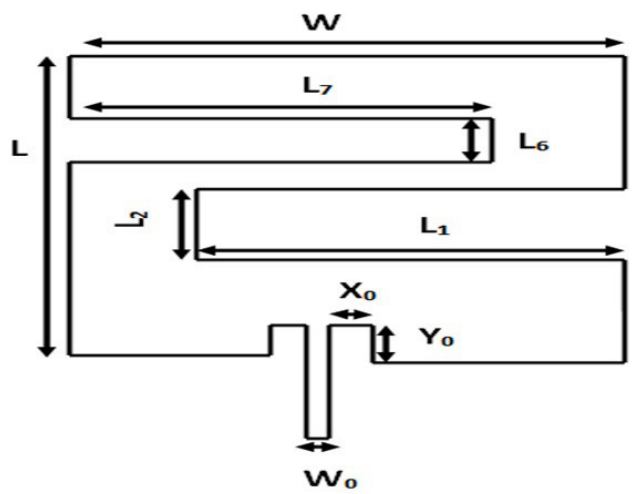

Fig. 2. Configurations of $Z$ - shape microstrip patch radiator

In patch antenna, the resistance at the edge of the radiating element and feed line impedance $(50 \mathrm{ohm})$ are always same which are usually few hundred ohms that depend on dimensions of radiating element and types of substrate used. As a result the maximum power is not being transferred and input mismatch influences the antenna performance. The input impedance of the rectangular patch radiator determines the matching among feed line and radiating element. As per transmission line theories, the resistance of the radiating element varies as a cosine squared function across the length of the radiating element. Following to theoretical calculations for the rectangular microstrip patch radiator, the proposed antenna $\mathrm{Z}$ - shape patch antenna is used for the desired output.

The steps of the design of Z- shape patch antenna are as follows.

$1^{\text {st }}$ step: The center frequency $\left(\mathrm{f}_{\mathrm{r}}\right)$, Dielectric constant $\left(\varepsilon_{\gamma}\right)$ and height $(\mathrm{h})$ of substrate are invaded in patch calculator which is programmed by MATLAB.

$2^{\text {nd }}$ step: The outputs $\mathrm{W}$ and $\mathrm{L}$ are used for designing $\mathrm{Z}$ shape radiator in High Frequency Structure Simulator.

$3^{\text {rd }}$ step: The implementation of designed radiator is analyzed in terms of $\mathrm{S}_{11}$, VSWR.

\section{Simulation Results}

The Z-shape patch antenna resonates at two bands of frequency at $3.3 \mathrm{GHz}$ and $4.2 \mathrm{GHz}$ which are related to the dimensions $\mathrm{L}_{1}, \mathrm{~L}_{2}$ and $\mathrm{L}_{6}, \mathrm{~L}_{7}$. These parameters are associated due to $50 \Omega$ impedance matching of single excitation point with two resonant frequencies. Rectangular patch radiator has been designed, simulated in high frequency structure simulator (HFSS) tool and performance of the designed Z-shape patch antenna (Fig. 1) are analyzed.

Return Loss: For better performance at resonance frequency the return loss should be minimal. The return loss plot for the designed Z- shaped patch antenna are shown in Fig.3. The Zshape patch exhibits return loss of -25.3 decibel at 3.3 Gigahertz and -15.7 decibel at 4.2 Gigahertz. The calculated value of $\mathrm{Z}$ - shape patch comes out to be $3.3 \mathrm{GHz}$ and 4.2 $\mathrm{GHz}$ with the antenna dimensions as given in table land matches well with the observed value $\quad \mathrm{f}_{0}=\frac{\mathrm{c}}{\mathrm{h}_{\mathrm{g}}}=\mathrm{c} / \mathrm{kL}$

Where k varies from $2,2.1 \ldots \ldots \ldots, 3$.

$\mathrm{f}_{1}=\frac{\mathrm{c}}{3 \mathrm{~L}}$ and $\mathrm{f}_{2}=\frac{\mathrm{c}}{2.3 \mathrm{~L}}$

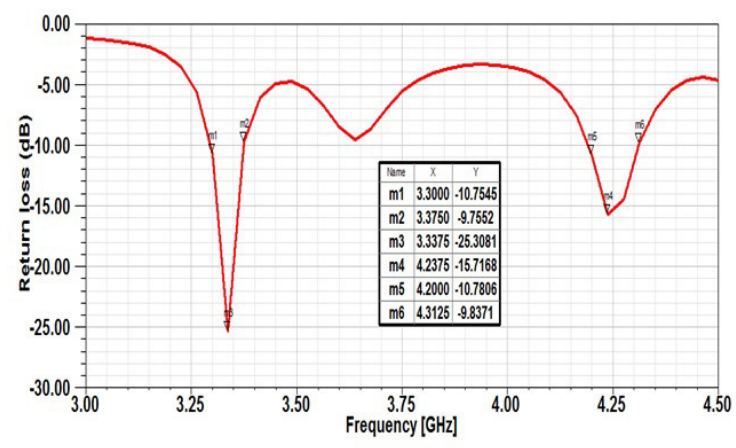

Fig 3. Return loss plot of Z- shape patch antenna

VSWR: Fig.4 shows the resultant VSWR of the intended optimized model. From Fig. 4 it is understandable that the Z- shape patch radiator has VSWR of $1.1,1.8$ at 3.3, 4.2 $\mathrm{GHz}$. 


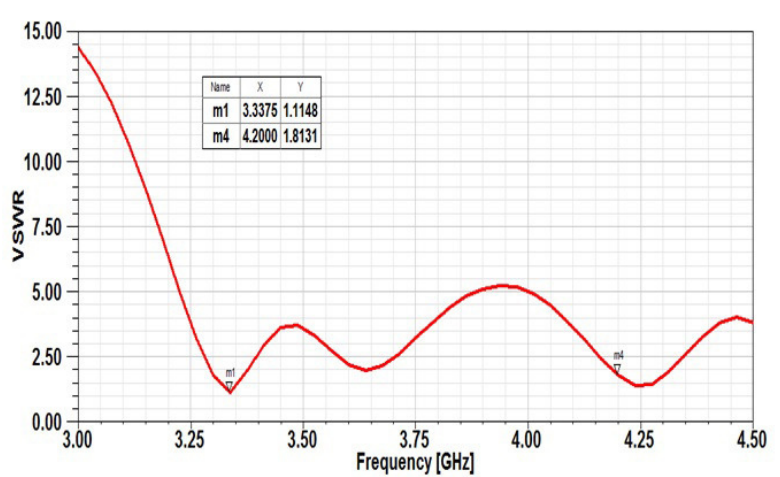

Fig. 4. VSWR Vs frequency plot of Z- shape patch antenna

Directivity: Fig. 5 shows the radiation pattern of the proposed antenna. For Z- shape patch antenna, the maximum directivity achieved is $6.31 \mathrm{~dB}$. 2-D Radiation pattern polar plot for $\Phi=0^{\circ}$ at the frequencies for Z-shape patch antenna is shown in Fig. 5.

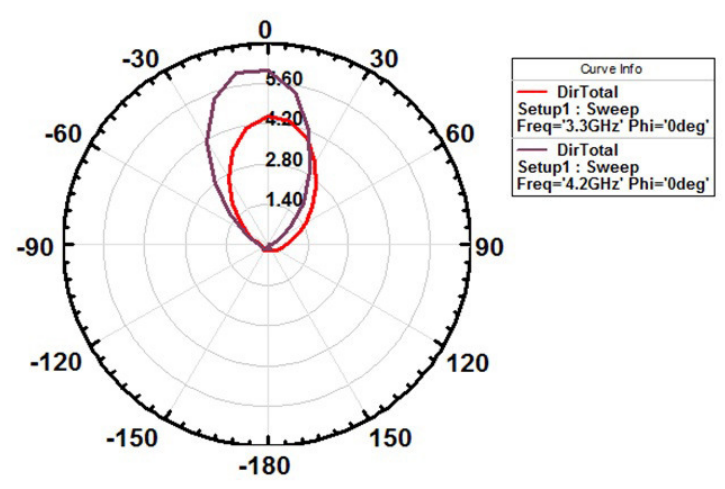

Fig 5. 2-D radiation pattern (polar plot) directivity of Z- shape patch radiator at 3.3 and $4.2 \mathrm{GHz}$

Gain: Fig. 6 exhibits the radiation patterns of the intended radiator. The gain versus frequency of the intended radiator is depicted in fig. 7 having maximum gain $2.8 \mathrm{dBi}$ at 4.4 $\mathrm{GHz}$. Basically the gain of antenna can be uniform or non uniform. The parameter antenna gain is nearly equivalent to directivity which is how much concentrates its energy in one direction leaning to radiation in other directions. For 100 percent antenna efficient, the directivity and gain would be same and the antenna would be an isotropic radiator.



Fig 6. 2-D radiation pattern (polar plot) gain of Z- shape patch antenna at 3.3 and $4.2 \mathrm{GHz}$



Fig 7. Gain versus frequency of Z- shape patch antenna 3.3 and $4.2 \mathrm{GHz}$

\section{CONCLUSION}

The proposed antenna Z-shape patch antenna will work in 3.3 and $4.2 \mathrm{GHz}$ frequency range which covers the frequency of operation of S- band and C- band satellite application. It supports the $4 \mathrm{G}, 5 \mathrm{G}$ and $\mathrm{NG}$ wireless communication systems. The simulated radiation pattern is partially Omni directional

\section{REFERENCES}

[1] D.M. Pozar, "Microstrip antennas", IEEE Transaction on Antenna and Propagation, Vol. 80, No.1, pp.79-91, 1992.

[2] R. Waterhouse, "Small Microstrip patch antenna", Electronics Letters, Vol. 31, No. 8, pp. 604-605, 1995.

[3] R Garg, P. Bhatia, I. Bahl and A. Ittipiboon, "Microstrip antenna Design Handbook", Chapters 3 \& 4, Artech House, Boston, London, 2001 .

[4] K. L. Lau, K. M. Luk and K. F. Lee, "Design of a circularly polarized vertical patch antenna", IEEE Transactions on Antennas and Propagation, Vol. 54, No.4, pp. 1332-1335, 2006.

[5] A. Das, M. N. Mohanty and L. P. Mishra, "EA Based Optimized T-Slot Patch Antenna for Bandwidth Improvement", IJET (Engineering Journals), Vol. 7, No. 4, pp. 1357-1360, 2015.

[6] S. Sahoo and M. N. Mohanty, "Design of Z- shape Microstrip Antenna with I-slot for Wi-MAX/ Satellite Application”, $11^{\text {th }}$ International Conference on Microwaves, Antenna, Propagation and Remote Sensing, ICMARS- 2015, Jodhpur, India, December 15-17, 2015.

[7] N. Misran, "Design and Development of Broadband Inverted Eshaped Patch Microstrip Array", American Journal of Applied Sciences, Vol. 5, No. 4, pp. 427-434, 2008.

[8] HFSS 13 - An soft 3D full-wave electromagnetic field software. http://www.ansoft.com/products/hf/hfss.

[9] M. Manzani, A. Alù, F. Bilotti, and L. Vegni, "Polygonal Patch Antenna for Wireless Communication", IEEE transanctions on vehicular technology. Vol. 53, No. 5, September 2004.

[10] T.A. Milligan, Modern Antenna Design, second edition, IEEE Press, John Wiley \& Sons inc., 2007.

[11] S. Maci and G. Biffi Gentilli, "Dual - frequency patch antennas", IEEE Transactions Antennas Propagation Mag 39, pp.13-20, 1997.

[12] R. Kumari and M. Kumar, "Diamond shaped Micro strip patch antenna for Dual Band Operation” IEEE Conference IMPACT, 2013.

[13] S. K. Singh, P. Consul and K. K Sharma, " Dual band gap coupled microstrip antenna using L- slot DGS for Wireless Applications" IEEE Conference ICCCA, 2015

[14] S. Mahapatra and M. N. Mohanty, "Simulation and Feed Analysis of Microstrip Antenna for UWB Communication", IEEE Conference ICCPCT 2014, 18 - 20 December 2014, Noorul Islam University, Kanyakumari, Tamilnadu, India. 